\section{A) Check for updates}

Cite this: Polym. Chem., 2017, 8 , 5780

Received 13th June 2017,

Accepted 18th July 2017

DOI: $10.1039 / c 7 p y 00985 b$

rsc.li/polymers

\title{
Ring opening polymerization of macrolactones: high conversions and activities using an yttrium catalyst $\uparrow$
}

\author{
D. Myers, ${ }^{a}$ T. Witt, (D) ${ }^{b}$ A. Cyriac, ${ }^{a}$ M. Bown, (D) ${ }^{c}$ S. Mecking (D) $\star^{b}$ and C. K. Williams (D) $\star^{a}, d$
}

\begin{abstract}
The ring-opening polymerization of macrolactones $\left(\mathrm{C}_{15}-\mathrm{C}_{23}\right)$ enables the production of long-chain aliphatic polyesters which are crystalline polymers with melting temperatures ranging from $98-106{ }^{\circ} \mathrm{C}$. Here, the polymerization of $\omega$-pentadecalactone $\left(C_{15}\right)$, nonadecalactone $\left(C_{19}\right)$ and tricosalactone $\left(C_{23}\right)$ are investigated using an yttrium phosphasalen catalyst. The catalyst enables typical conversions to exceed $>80 \%$ and the reactions occur either in neat monomer or in solution in toluene, over the temperature range $25-100{ }^{\circ} \mathrm{C}$. The yttrium catalyst shows higher activities than previously reported aluminium-salen complexes, with TOF values in the range $200-400 \mathrm{~h}^{-1}$ in the best cases. The polymerizations occur with linear increase in molecular weight vs. conversion and enable the production of polyester with $10<M_{n}<$ $60 \mathrm{~kg} \mathrm{~mol}^{-1}$. Using tricosalactone the polymerization thermodynamic parameters are determined and confirm the polymerization is entropically driven. The findings underscore the importance of continued catalyst development to allow higher rates of reaction which has the added benefit of accessing the highest conversions to polymer.
\end{abstract}

\section{Introduction}

Aliphatic polyesters may be sustainable alternatives to petrochemically-derived commercial polymers, especially where they are bio-derived and/or degradable. ${ }^{1}$ In this context, the search for alternatives to polyolefins, such as polyethylene (PE), are particularly important due to the enormous current scales of polyolefin production and usage. ${ }^{1 e, 2}$ Long-chain aliphatic polyesters show promise as more sustainable alternatives - they are able to match the properties of some classes of $\mathrm{PE}$, for example showing melting temperatures, crystallinity and tensile strengths akin to PE. ${ }^{1 c, 3}$ Furthermore, natural triglycerides, extracted from plants or even bio-synthesized by algae, can be used as the sources of the monomers. ${ }^{2}$ The polyesters can be produced by either condensation routes or by the ring-opening polymerizations (ROP) of macrolactones. ${ }^{4}$ Although both methods are successful and could be compatible with larger scale processes, the ring-opening polymeriz-

\footnotetext{
${ }^{a}$ Department of Chemistry, Imperial College London, London SW7 2AZ, UK

${ }^{b}$ Department of Chemistry, University of Konstanz, Universitätsstraße 10, 78457 Konstanz, Germany.E-mail: stefan.mecking@uni-konstanz.de ${ }^{c}$ CSIRO Manufacturing, Ian Wark Laboratory, Bayview Avenue, Clayton, Vic 3168, Australia

${ }^{d}$ Department of Chemistry, University of Oxford, Chemistry Research Laboratory, 12 Mansfield Road, Oxford, OX1 3 TA, UK

$\dagger$ Electronic supplementary information (ESI) available: Experimental section, NMR spectra and polymer characterization data. See DOI: 10.1039/c7py00985b
}

ation is a chain growth reaction and so at the same conversion higher molecular weights should be achieved. Further, using ROP it is possible to control the molar mass and chain endgroups, and to produce copolymers. There has been a growing body of work demonstrating the promising physical-chemical properties for both homo- and copolymers prepared from macrolactones, most especially using $\omega$-pentadecalactone (PDL). ${ }^{3,5}$ Nonetheless, a difference between ROP using macrolactones, compared to smaller lactones, is that there are generally similar rates of propagation and transesterification leading to broader molecular weight dispersity values and hindering block copolymer synthesis.

Lactone ring-opening polymerization is also used commercially to prepare aliphatic polyesters such as polylactide. In the case of small ring sizes ( $<7$ membered ring), the reaction is enthalpy driven and results in a release of ring-strain upon polymer formation. ${ }^{1 a, 7}$ Substantial research has focussed on these smaller ring systems - there is good understanding of the thermodynamic factors controlling ring-strain and the kinetic factors enabling the production of more efficient catalysts. In contrast, larger ring-systems are less explored but are generally expected to undergo entropically driven polymerizations. ${ }^{5 l, 6 b, 8}$ The macrolactone $\omega$-pentadecalactone (PDL) $\left(\mathrm{C}_{15}\right)$ has been most widely explored and its thermodynamic parameters are consistent with entropy driven reactions: $\Delta H_{\mathrm{p}}^{\circ}=3 \mathrm{~kJ} \mathrm{~mol}^{-1}$ and $\Delta S_{\mathrm{p}}^{\circ}=23 \mathrm{~J} \mathrm{~mol}^{-1} \mathrm{~K}^{-1}\left([\mathrm{PDL}]_{\mathrm{eq}}=0.016 \mathrm{M}\right.$ at $373 \mathrm{~K})^{7}$ Its polymerization was pioneered more than 20 years ago using lipase enzymes ${ }^{5 a, e, 9}$ and has also been reported 
using various metal ${ }^{6 a, 10}$ and organic catalysts. ${ }^{11}$ It was noted that the metal based catalysts typically showed greater activity and productivity compared to enzyme systems under comparable conditions. ${ }^{10 d}$ Two of the best metal catalysts are lanthanide/Group 3 complexes: Nakayama et al., reported $\left[\mathrm{Nd}\left(\mathrm{BH}_{4}\right)_{3}(\mathrm{THF})_{3}\right]$ with a TOF of $343 \mathrm{~min}^{-1}\left([\mathrm{PDL}]_{0}=2.76 \mathrm{M}\right.$, $[\mathrm{Nd}]_{0}=0.018 \mathrm{M}, 83 \%$ conversion, THF, $\left.60{ }^{\circ} \mathrm{C}\right)^{10 d}$ and Zhong et al., reported yttrium(tris(iso-propoxide)) showing a TOF of $214 \mathrm{~min}^{-1}\left([\mathrm{PDL}]_{0}=3.8 \mathrm{M}\right.$ (neat), $[\mathrm{Y}]_{0}=9.5 \mathrm{mM}, 70 \%$ conversion, $\left.100{ }^{\circ} \mathrm{C}\right) .{ }^{10 b}$ In contrast, Al-salen catalysts, which are widely available, showed TOF in the range $1-4 \mathrm{~min}^{-1}\left([\mathrm{PDL}]_{0}=\right.$ $1 \mathrm{M},[\mathrm{Al}]_{0}=0.01 \mathrm{M}$, toluene, $\left.100^{\circ} \mathrm{C}\right) .{ }^{6 e}$

In the broader context of macrolactone ROP, the investigation of ring sizes greater than $\mathrm{C}_{15}$ (PDL) remains much less explored. ${ }^{5 j, 6 a, d, e, 12}$ We recently reported the preparation of nonadecalatone $\left(\mathrm{C}_{19}\right)$ and tricosalactone $\left(\mathrm{C}_{23}\right)$ from fatty acids. ${ }^{6 e}$ The ROP of these larger lactones was initially investigated using aluminium-salen catalysts and more recently successfully using lipase enzymes. In the case of the $\mathrm{Al}-$ salen catalysts, the polymerizations showed very low rates (NDL: average and unoptimized TOF $=4 \mathrm{~h}^{-1}$; TCL: average and unoptimized $\mathrm{TOF}=0.7 \mathrm{~h}^{-1} ;[\text { lactone }]_{0}=3.8 \mathrm{M}$ (bulk), $[\mathrm{Al}]_{0}=0.25 \mathrm{~mol} \%$, $100{ }^{\circ} \mathrm{C}$ ) and overall conversions were very low $-23 \%$ (NDL) and $5 \%$ (TCL) (Fig. 1). ${ }^{6 e}$ We recently reported the use of yttrium phosphasalen catalysts which show high activity and control in the ring-opening polymerization of lactide..$^{13}$ Given the poor performances of Al-salen catalysts in macrolactone ROP, it was of interest to investigate whether an yttrium-phosphasalen catalyst could be used to increase rates and overall conversions to polyester using the new macrolactones (Scheme 1).

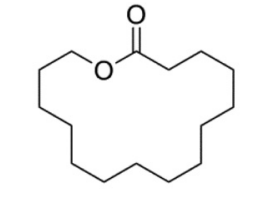

$\omega$-pentadecalactone (PDL)

Conv. $=70 \%$, time $=1 \mathrm{~h}$

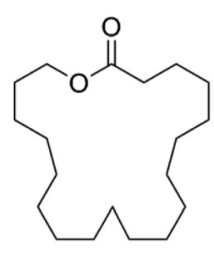

Nonadecalactone (NDL)

Conv. $=23 \%$, time $=22 \mathrm{~h}$

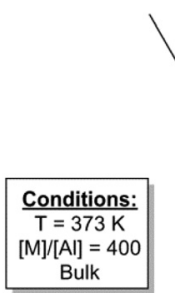

ulk
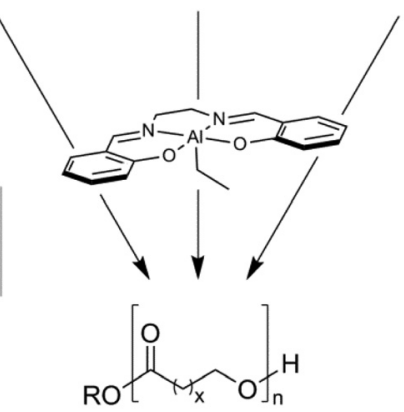

$x=13$; PPDL $\quad x=17$; PNDL $\quad x=21$; PTCL

Fig. 1 Ring-opening polymerizations of macrolactones catalyzed by an aluminium salen complex. ${ }^{6 e}$

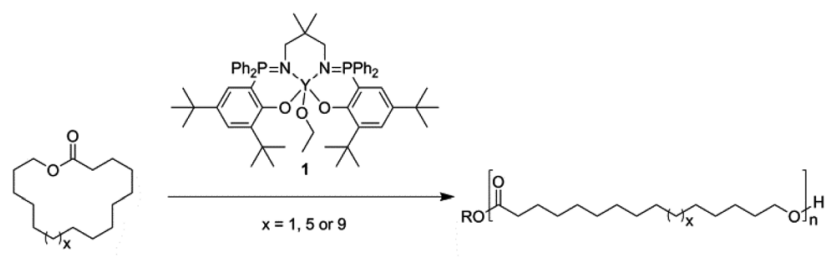

Scheme 1 Yttrium phosphasalen catalysed ring-opening polymerisation of macrolactones: PDL $\left(\mathrm{C}_{15}\right), \mathrm{NDL}\left(\mathrm{C}_{19}\right)$ and $\mathrm{TCL}\left(\mathrm{C}_{23}\right)$. Conditions: $[\text { Lactone }]_{0} /[1]=50-200,[\text { Lactone }]_{0}=0.3-3.8 \mathrm{M}$, toluene or bulk.

\section{Results and discussion}

The yttrium catalyst (1), ${ }^{13 a} \mathrm{NDL}^{6 e}$ and $\mathrm{TCL}^{6 e}$ were synthesized according to published procedures and PDL was purchased and purified by distillation from $\mathrm{CaH}_{2}$. Firstly, the ROP of $\omega$-pentadecalactone (PDL) was investigated in bulk monomer $\left([\mathrm{PDL}]_{0}=3.8 \mathrm{M}\right)$, at $373 \mathrm{~K}$, using $1 \mathrm{~mol} \%$ loading of yttrium catalyst (vs. monomer) (Table 1 , entry 1 ). The reaction proceeded very rapidly as shown by near complete conversion to polymer occurring within $10 \mathrm{~s}$, which equates to a turn-overfrequency of TOF $\sim 126000 \mathrm{~h}^{-1}$ or $2100 \mathrm{~min}^{-1}$ (Fig. S1-S3†). Whilst a number of catalysts are reported for the ROP of PDL, the rates observed using 1 are qualitatively fast: $c a$. 6 times faster than the Nd complex (TOF $=330 \mathrm{~min}^{-1}$, albeit measured at lower temperature), 16 times faster than the yttrium complex $\left(\mathrm{TOF}=124 \mathrm{~min}^{-1}\right)$, and 1200 times faster than the $\mathrm{Al}-$ salen complex $\left(\mathrm{TOF}=1.7 \mathrm{~min}^{-1}\right) \cdot{ }^{5 j, 10 b, d_{f} f}$

In order to allow monitoring of the reaction, polymerizations were also investigated using a $1 \mathrm{M}$ solution of monomer in toluene, at room temperature and using a $1 \mathrm{~mol} \%$ loading of the yttrium catalyst. The conditions were selected both to decrease the reaction rate and to enable understanding of the temperature range feasible for successful catalysis. Under these conditions, catalyst 1 enabled quantitative conversion of PDL to polyester within $4 \mathrm{~h}$, i.e. TOF $=25 \mathrm{~h}^{-1}$ (Table 1, entry 2) (Fig. S4 and S5†). The ability to catalyse polymerizations at room temperature was somewhat surprising but maybe useful as a means to increase conversion, it was previously reported that other fast catalysts do not operate at room temperature. ${ }^{10 d}$

The kinetics of the polymerisation at room temperature were analysed by regularly withdrawing aliquots from the reaction mixture. The analysis revealed a first-order rate dependence on monomer concentration and enabled determination of $k_{\text {obs }}=2.28 \pm 0.05 \times 10^{-4} \mathrm{~s}^{-1}$ (Fig. S6 and S7 $\dagger$ ). The polymer number average molecular weight $\left(M_{\mathrm{n}}\right)$ was determined using size-exclusion chromatography (SEC) with trichlorobenzene as the eluent, at $433 \mathrm{~K}$ and the instrument was calibrated with narrow molecular weight polyethylene standards. The analysis showed a linear evolution of $M_{\mathrm{n}}$ vs. monomer conversion, indicating a reasonably well-controlled polymerization, with experimental and theoretical values of molecular weight in good agreement (Fig. S8†). The dispersity values were around 2, which is as expected for macrolactone ROP and can be understood in terms of relatively similar rates of propagation and transesterification. ${ }^{5 l}$ 
Table 1 Polymerisation of macrolactones (LA) by an yttrium phosphasalen initiator, $1^{a}$

\begin{tabular}{|c|c|c|c|c|c|c|c|c|c|c|}
\hline Entry & Lactone & $T(\mathrm{~K})$ & {$[\mathrm{LA}]_{0} /[1]$} & {$[\text { Lactone }]_{0}(\mathrm{M})$} & Conv. $^{c}(\%)$ & Time (h) & TOF $\left(\mathrm{mol} \mathrm{mol}^{-1} \mathrm{~h}^{-1}\right)$ & $M_{\mathrm{n}}^{\text {theo } d}\left(\mathrm{~kg} \mathrm{~mol}^{-1}\right)$ & $M_{\mathrm{n}}^{\exp e}\left(\mathrm{~kg} \mathrm{~mol}^{-1}\right)$ & $D^{e}$ \\
\hline 2 & PDL & 298 & 100 & 1.0 & 98 & 4 & 25 & 23.6 & 26.1 & 2.06 \\
\hline $5^{b}$ & NDL & 298 & 100 & 3.0 & 33 & 25 & 4 & 9.8 & 27.0 & 2.55 \\
\hline $6^{b}$ & NDL & 373 & 100 & 3.0 & 78 & 1 & 234 & 23.1 & 8.6 & 2.40 \\
\hline 7 & NDL & 373 & 100 & 0.75 & 86 & $10 \mathrm{~min}$ & 387 & 25.5 & 18.4 & 2.17 \\
\hline 10 & NDL & 373 & 200 & 0.3 & 77 & $10 \mathrm{~min}$ & 277 & 45.6 & 24.3 & 2.22 \\
\hline 11 & TCL & 373 & 100 & 0.3 & 83 & $20 \mathrm{~min}$ & 75 & 29.3 & 21.5 & 2.54 \\
\hline 12 & TCL & 373 & 50 & 0.3 & 97 & $5 \mathrm{~min}$ & 175 & 17.1 & 12.0 & 2.14 \\
\hline 13 & TCL & 373 & 200 & 0.3 & 85 & $90 \min$ & 34 & 59.9 & 32.1 & 2.18 \\
\hline
\end{tabular}

${ }^{a}$ Solvent $=$ toluene. ${ }^{b}$ No solvent. ${ }^{c}$ Monomer conversion determined by ${ }^{1} \mathrm{H}$ NMR spectroscopy. ${ }^{d}$ Theoretical molecular weight determined by the following relation: $M_{\mathrm{n}}^{\text {theo }}=$ molecular weight of monomer $\times$ conversion $\times$ no. of equivalents. ${ }^{e}$ Determined by SEC analysis (trichlorobenzene, $433 \mathrm{~K}, \mathrm{PE}$ standards).

Even when the monomer concentration was further decreased, near-quantitative conversions were still achievable even using $[\mathrm{PDL}]_{0}=0.25 \mathrm{M}(298 \mathrm{~K})$ (Table 1, entry 3; Fig. S11 and $\mathrm{S} 12 \dagger)$. In the context of the thermodynamic parameters, Duda and Kowalski determined that $[\mathrm{PDL}]_{\mathrm{eq}}=0.7 \mathrm{M}(T=$ $370 \mathrm{~K})$ a value that was calculated from experimental data reported by Lebedev and co-workers. ${ }^{14}$ On that basis, at low monomer concentrations $([\mathrm{PDL}]<0.7 \mathrm{M})$, polymerization would not be expected to proceed - a finding clearly at odds with the experimental results. Nonetheless, Duchateau and coworkers recently reported polymerizations at monomer concentrations as low as $[\mathrm{PDL}]_{0}=0.25 \mathrm{M}(T=373 \mathrm{~K}) .{ }^{10 e}$ Duchateau and co-workers determined a lower value for the equilibrium monomer concentration: $[\mathrm{PDL}]_{\mathrm{eq}}=0.016 \mathrm{M}(T=373 \mathrm{~K}) .{ }^{10 e}$ They attributed the difference between the equilibrium monomer concentrations to experimental limitations in the earlier report where extensive purification was used to isolate the polymer. ${ }^{10 e}$ Accordingly during purification low molecular weight polymer fractions would be removed, resulting in an under-estimation of polymer yield and an artificially high equilibrium monomer concentration. ${ }^{10 e}$ Here, the experimental protocol did not involve any isolation and so the equilibrium monomer concentration value is expected to be in line with that determined by Duchateau and co-workers. ${ }^{10 e}$

Polymerisations were also investigated at lower catalyst loadings $\left([\mathrm{PDL}] /[1]=500,0.2 \mathrm{~mol} \%,[\mathrm{PDL}]_{0}=1 \mathrm{M}\right.$, at $\left.373 \mathrm{~K}\right)$ and proceeded effectively to give TOF $=660 \mathrm{~h}^{-1}$ (Table 1 , entry 4; Fig. S13 and S14 ). It is quite notable that the catalysts were successful at both low monomer and catalyst concentrations there are few equivalent reports for other catalysts. ${ }^{5 j, 11 d}$ One example, reported by Duchateau et al.,${ }^{12}$ showed approximately equivalent conversion (57\%) but requiring an hour using similar loadings $\left([\mathrm{PDL}] /[\mathrm{Al}]=433,0.23 \mathrm{~mol} \%,[\mathrm{PDL}]_{0}=1.3 \mathrm{M}\right.$, at $373 \mathrm{~K})$.

Encouraged by the activity of $\mathbf{1}$ for the ROP of PDL, the use of nonadecalactone (NDL) was subsequently investigated. As mentioned, the previous ROP of NDL applied an aluminium salen catalyst and resulted in $23 \%$ conversion after $22 \mathrm{~h}$, i.e. TOF $=4 \mathrm{~h}^{-1}(T=373 \mathrm{~K}) .{ }^{10}$ The first polymerizations were investigated using neat monomer at $298 \mathrm{~K}$ (note that NDL is liquid at this temperature) and applying $1 \mathrm{~mol} \%$ of catalyst 1 . Even under these low temperature conditions, catalyst 1 enabled $33 \%$ conversion within $25 \mathrm{~h}$, i.e. TOF $=1 \mathrm{~h}^{-1}$ - with the overall conversion surpassing that previously obtained with Al-salen catalysts even at the lower reaction temperature $(373 \mathrm{~K} v s$. $298 \mathrm{~K}$ ) (Fig. S15-S17†). It was also noted that the polymer precipitated, which prevented efficient agitation and so allows only approximate estimation of activity. The SEC analysis revealed that polymer molecular weights were significantly higher than expected, consistent with the heterogeneity of the reaction (Table 1, entry 5). In order to prevent polymer precipitation, the polymerisation was investigated using neat monomer, at $373 \mathrm{~K}$, and under fully homogeneous conditions, the TOF increased to $234 \mathrm{~h}^{-1}$ (Table 1, entry 6; Fig. S18 and S19†). Further experiments revealed that the conversion could be increased to $94 \%$ by conducting the polymerisation in toluene (Fig. S20 and S21 $\dagger$ ). Through appropriate tuning of conditions, TOF values up to $387 \mathrm{~h}^{-1}$ were feasible (Table 1, entry 7) with molecular weights close to predicted values (Fig. S22 and S23†).

The polymerization kinetics for NDL ROP were investigated by quenching a series of separate polymerizations at specific time intervals and the crude mixtures were analysed using ${ }^{1} \mathrm{H}$ NMR spectroscopy so as to determine the conversions of monomer and polymer (see ESI $\dagger$ ). Analysis of the aliquots showed the high polymerization control exhibited by catalyst $\mathbf{1}$, with SEC analysis revealing a linear growth in molecular weights against conversion (Table 1, entries 8-10; Fig. S24-S29†).

Finally, the ROP of the larger tricosalactone $\left(\mathrm{C}_{23}\right)$ was investigated. After $20 \mathrm{~min}$, using toluene solutions at $373 \mathrm{~K}$ $\left([\mathrm{TCL}] /[1]=100,[\mathrm{TCL}]_{0}=0.3 \mathrm{M}\right.$, toluene and $\left.T=373 \mathrm{~K}\right)$, conversions of $83 \%$ were achieved, i.e. TOF $=75 \mathrm{~h}^{-1}$ (Table 1, entry 11; Fig. S30-S32†). Both the conversion and the turn over frequency of the catalyst were significantly greater than the 
previous report for TCL ROP using an aluminium salen catalyst $\left(\mathrm{TOF}=1 \mathrm{~h}^{-1}\right) .{ }^{6 e}$ Overall, the results using both NDL and TCL show that the low conversions obtained using Al-salen catalysts were a feature of low reaction rates and can be improved using the more active yttrium catalysts.

Next, the polymerization kinetics using TCL were obtained by quenching reactions at specific time intervals and analysing the crude mixtures by NMR spectroscopy (see ESI $\dagger$ ). The semilogarithmic plot of monomer concentration against time showed a linear fit indicating a first-order dependence on [TCL] and enabling determination of $k_{\text {obs }}=3.06 \pm 0.31 \times 10^{-3} \mathrm{~s}^{-1}$ (Fig. 2). The equivalent rate constant for PDL ROP, under identical conditions, is $k_{\mathrm{obs}}=1.01 \pm 0.11 \times 10^{-3} \mathrm{~s}^{-1}-i . e$. TCL is polymerized approximately three times faster than PDL using catalyst 1 (Fig. S33 and S34†).

The ROP of TCL catalyzed by $\mathbf{1}$ also showed a linear evolution of molecular weights with conversion, indicating good polymerization control. In line with these findings, the PTCL molecular weights were controlled by the catalyst loading and values in the range $17-60 \mathrm{~kg} \mathrm{~mol}{ }^{-1}$ were obtained (Table 1, entries 11-13; Fig. S35-S38 $\dagger$ ). In order to further examine the ROP of TCL, a Van 't Hoff analysis was performed. The determination of [TCL $]_{\text {eq }}$ was conducted by carrying out polymerizations at various temperatures. For each reaction, exponential fits to monomer conversion vs. time allowed determination of the $k_{\text {obs }}$ values, the fits were in accordance with the first order dependence in monomer concentration and were carried out over $>5.5$ half-lives (Fig. S39-S42 $\dagger$ ). It is important to emphasise that the results are best described as semiquantitative since monomer and polymer resonances were observed to overlap in the NMR spectra and conversions required the use of peak deconvolution techniques (see $\operatorname{ESI} \dagger$ ). The thermodynamic parameters were determined as: $\Delta H_{\mathrm{p}}^{\circ}=-7.6 \pm 2.1 \mathrm{~kJ} \mathrm{~mol}^{-1}$ and $\Delta S_{\mathrm{p}}^{\circ}=8.4 \pm 5.7 \mathrm{~J} \mathrm{~mol}^{-1} \mathrm{~K}^{-1}$ (Fig. S43†). Despite some uncertainty in the absolute values, particularly for the entropy, the equilibrium monomer concentration was determined to be $0.03 \mathrm{M}(373 \mathrm{~K})$ and was clearly independent of the reaction temperature, as would be expected for an entropically driven ROP. The values obtained for TCL ROP are in line with the thermodynamic parameters for other macrolactones, e.g. PDL has been reported to show $\Delta H_{\mathrm{p}}^{\circ}=3 \mathrm{~kJ} \mathrm{~mol}^{-1}$ and $\Delta S_{\mathrm{p}}^{\circ}=23 \mathrm{~J} \mathrm{~mol}^{-1} \mathrm{~K}^{-1},{ }^{7}$ and the 17 -membered lactone ambrettolide, $\Delta H_{\mathrm{p}}^{\circ}=0.9 \mathrm{~kJ} \mathrm{~mol}^{-1}$ and $\Delta S_{\mathrm{p}}^{\circ}=38.5 \mathrm{~J} \mathrm{~mol}^{-1} \mathrm{~K}^{-1} \cdot{ }^{5 l}$

In terms of the polymers produced from the macrolactones, DSC analyses revealed crystalline polyesters with melting temperatures $\left(T_{\mathrm{m}}\right)$ at $102{ }^{\circ} \mathrm{C}$ (PNDL) and $106{ }^{\circ} \mathrm{C}$ (PTCL) (Table 1, entries 10 and 13; Fig. 3; Fig. S44 and S45†). The small increase in $T_{\mathrm{m}}$ for PTCL was attributed to the higher concentration of methylene groups in the main chain compared to PNDL (ESI $\dagger$ ). In line with the findings, for PPDL $T_{\mathrm{m}}=$ $97^{\circ} \mathrm{C} .{ }^{5 c}$
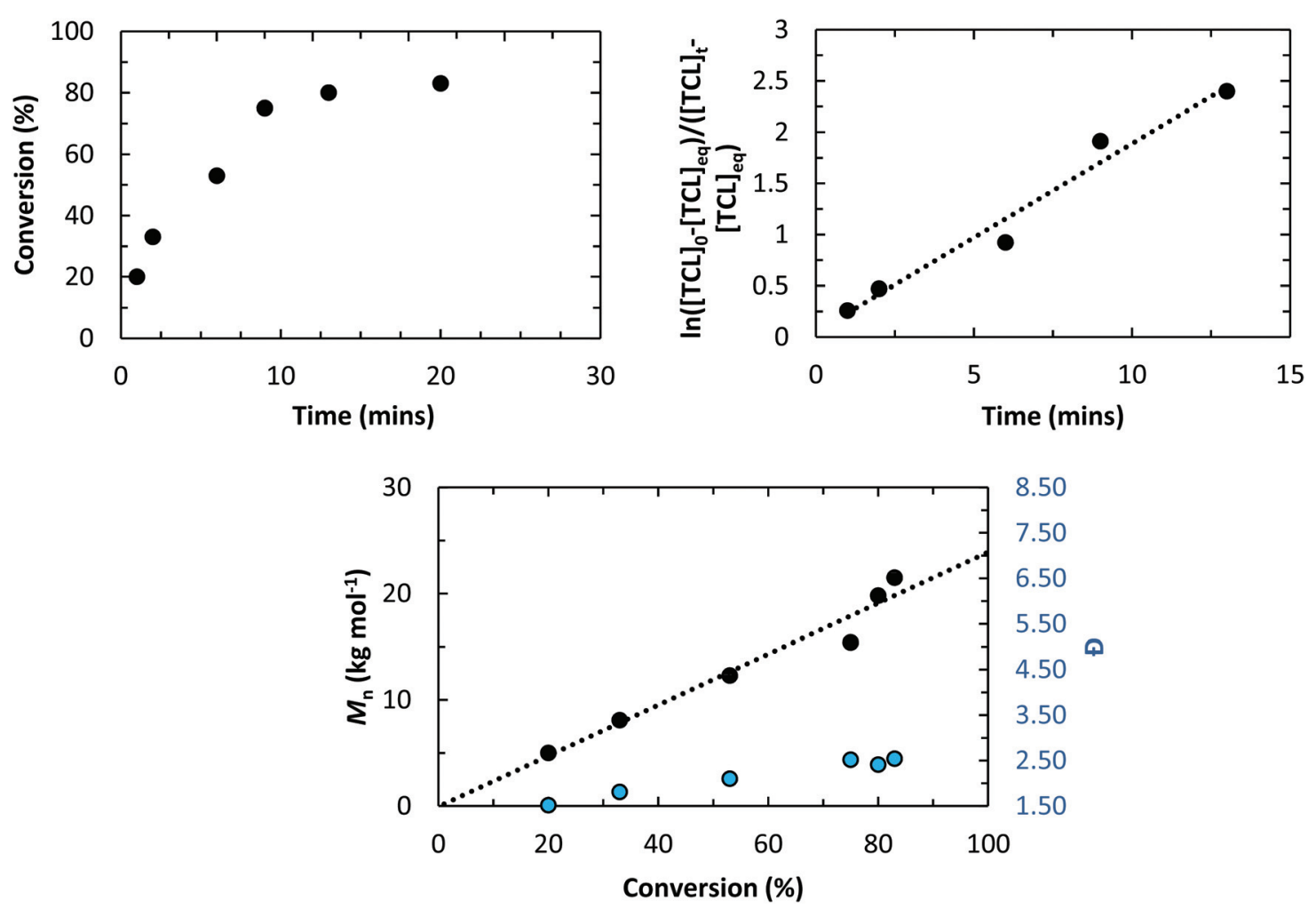

Fig. 2 Polymerisation data for the ROP of TCL. Conversion vs. time plot (top left), semi-logarithmic pseudo first-order kinetic plot (top right) and molecular weight evolution with $\ominus$ vs. conversion (bottom). Conditions: $[T C L]_{0} /[1]=100,[T C L]_{0}=0.3 \mathrm{M}$, toluene, $373 \mathrm{~K}$. 


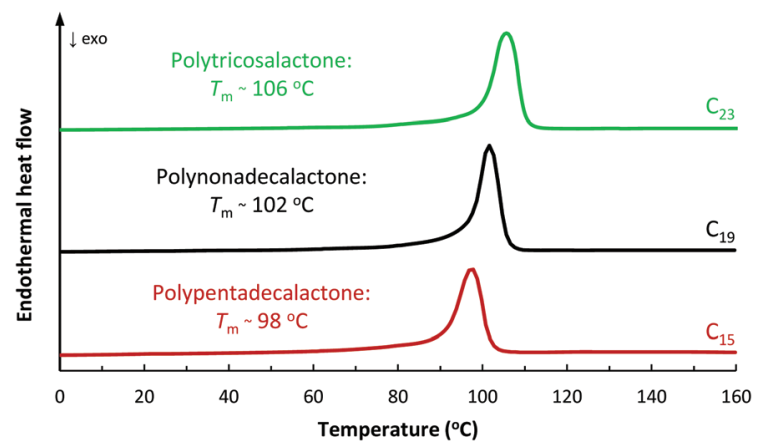

Fig. 3 DSC thermograms of PPDL, PNDL and PTCL samples. The PPDL sample is shown for comparative purposes and was prepared using an aluminium salen initiator. Second heating cycles shown.

\section{Conclusions}

A highly active yttrium phosphasalen catalyst showed efficient and controlled ROP of three macrolactones: pentadecalactone (PDL), nonadecalactone (NDL) and tricosalactone (TCL). The catalyst showed rapid rates, with TOF values in the range 200-400 $\mathrm{h}^{-1}$ for NDL $\left(100{ }^{\circ} \mathrm{C},[\mathrm{NDL}]=0.3-0.75 \mathrm{M}\right.$, toluene $)$ and $34-175 \mathrm{~h}^{-1}$ for TCL $\left(100{ }^{\circ} \mathrm{C}\right.$, [TCL] $=0.3 \mathrm{M}$, toluene $)$. The polymerizations were effective under a range of conditions, including either in neat monomer or as solutions diluted in toluene, and the catalyst operated effectively over a broad temperature range: $25-100{ }^{\circ} \mathrm{C}$. The rapid rates allowed high conversions to polyester (NDL: $86 \%$, TCL: $97 \%$ ) which is a significant improvement compared to previous investigations using Al-salen catalysts. In addition to high rates and overall conversions, the polymerizations were well controlled yielding polymers with molecular weights in the range $10-60 \mathrm{~kg} \mathrm{~mol}^{-1}$ together with broad dispersity values $(\nexists \sim 2)$. The polymerization thermodynamic parameters were determined for tricosalactone. The polymerization is entropically driven and the equilibrium monomer conversion is $0.03 \mathrm{M}(373 \mathrm{~K})$. Overall, the findings demonstrate the relevance and potential for catalyst development in macrolactone ROP. It is likely that further optimization of catalyst and conditions will enable the more efficient production of long-chain aliphatic polyesters, as class of materials with thermal properties akin to those of polyethylene but which are distinctive by being degradable.

\section{Acknowledgements}

The EPSRC (EP/L017393/1) and CSIRO-Imperial College London PhD Studentship are acknowledged for research funding. Financial support by the Stiftung BadenWürttemberg to T. W. and S. M. is acknowledged.

\section{References}

1 (a) M. A. Hillmyer and W. B. Tolman, Acc. Chem. Res., 2014, 47, 2390-2396; (b) S. Slomkowski, S. Penczek and A. Duda,
Polym. Adv. Technol., 2014, 25, 436-447; (c) F. Stempfle, P. Ortmann and S. Mecking, Chem. Rev., 2016, 116, 45974641; (d) J. M. Longo, M. J. Sanford and G. W. Coates, Chem. Rev., 2016, 116, 15167-15197; (e) Y. Zhu, C. Romain and C. K. Williams, Nature, 2016, 540, 354-362; $(f)$ R. P. Brannigan and A. P. Dove, Biomater. Sci., 2017, 5, 9-21.

2 L. Maisonneuve, T. Lebarbé, E. Grau and H. Cramail, Polym. Chem., 2013, 4, 5472-5517.

3 (a) K. S. Bisht, L. A. Henderson, R. A. Gross, D. L. Kaplan and G. Swift, Macromolecules, 1997, 30, 2705-2711; (b) I. van der Meulen, M. de Geus, H. Antheunis, R. Deumens, E. A. J. Joosten, C. E. Koning and A. Heise, Biomacromolecules, 2008, 9, 3404-3410.

4 C. Liu, F. Liu, J. Cai, W. Xie, T. E. Long, S. R. Turner, A. Lyons and R. A. Gross, Biomacromolecules, 2011, 12, 3291-3298.

5 (a) A. Kumar, B. Kalra, A. Dekhterman and R. A. Gross, Macromolecules, 2000, 33, 6303-6309; (b) A. Kumar, K. Garg and R. A. Gross, Macromolecules, 2001, 34, 3527-3533; (c) M. L. Focarete, M. Scandola, A. Kumar and R. A. Gross, J. Polym. Sci., Part B: Polym. Phys., 2001, 39, 1721-1729; (d) Z. Z. Jiang, H. Azim, R. A. Gross, M. L. Focarete and M. Scandola, Biomacromolecules, 2007, 8, 2262-2269; (e) J. L. Cai, B. S. Hsiao and R. A. Gross, Polym. Int., 2009, 58, 944-953; $(f)$ M. Eriksson, L. Fogelstrom, K. Hult, E. Malmstrom, M. Johansson, S. Trey and M. Martinelle, Biomacromolecules, 2009, 10, 3108-3113; (g) J. L. Cai, C. Liu, M. M. Cai, J. Zhu, F. Zuo, B. S. Hsiao and R. A. Gross, Polymer, 2010, 51, 1088-1099; (h) M. de Geus, I. van der Meulen, B. Goderis, K. van Hecke, M. Dorschu, H. van der Werff, C. E. Koning and A. Heise, Polym. Chem., 2010, 1, 525-533; (i) J. L. Cai, B. S. Hsiao and R. A. Gross, Macromolecules, 2011, 44, 3874-3883; (j) I. van der Meulen, E. Gubbels, S. Huijser, R. Sablong, C. E. Koning, A. Heise and R. Duchateau, Macromolecules, 2011, 44, 4301-4305; (k) M. P. F. Pepels, M. R. Hansen, H. Goossens and R. Duchateau, Macromolecules, 2013, 46, 7668-7677; (l) M. P. F. Pepels, P. Soulje, R. Peters and R. Duchateau, Macromolecules, 2014, 47, 5542-5550; (m) L. Jasinska-Walc, M. R. Hansen, D. Dudenko, A. Rozanski, M. Bouyahyi, M. Wagner, R. Graf and R. Duchateau, Polym. Chem., 2014, 5, 3306-3310; (n) L. Jasinska-Walc, M. Bouyahyi, A. Rozanski, R. Graf, M. R. Hansen and R. Duchateau, Macromolecules, 2015, 48, 502-510; (o) M. P. F. Pepels, L. E. Govaert and R. Duchateau, Macromolecules, 2015, 48, 5845-5854; ( $p$ ) M. P. F. Pepels, W. P. Hofman, R. Kleijnen, A. B. Spoelstra, C. E. Koning, H. Goossens and R. Duchateau, Macromolecules, 2015, 48, 6909-6921; (q) M. P. F. Pepels, R. A. C. Koeken, S. J. J. van der Linden, A. Heise and R. Duchateau, Macromolecules, 2015, 48, 4779-4792; (r) R. Todd, S. Tempelaar, G. Lo Re, S. Spinella, S. A. McCallum, R. A. Gross, J. M. Raquez and P. Dubois, ACS Macro Lett., 2015, 4, 408-411; (s) S. Spinella, M. Ganesh, G. Lo Re, S. Zhang, J. M. Raquez, P. Dubois and R. A. Gross, Green Chem., 2015, 17, 4146-4150; 
$(t)$ J. A. Wilson, S. A. Hopkins, P. M. Wright and A. P. Dove, Biomacromolecules, 2015, 16, 3191-3200; (u) J. A. Wilson, S. A. Hopkins, P. M. Wright and A. P. Dove, Macromolecules, 2015, 48, 950-958; (v) M. P. F. Pepels, F. van der Sanden, E. Gubbels and R. Duchateau, Macromolecules, 2016, 49, 4441-4451; (w) J. A. Wilson, S. A. Hopkins, P. M. Wright and A. P. Dove, ACS Macro Lett., 2016, 5, 346-350; (x) S. Rutkowski, A. Zych, M. Przybysz, M. Bouyahyi, P. Sowinski, R. Koevoets, J. Haponiuk, R. Graf, M. R. Hansen, L. Jasinska-Walc and R. Duchateau, Macromolecules, 2017, 50, 107-122; (y) J. Fernández, H. Amestoy, H. Sardon, M. Aguirre, A. L. Varga and J.-R. Sarasua, J. Mech. Behav. Biomed. Mater., 2016, 64, 209219.

6 (a) R. Nomura, A. Ueno and T. Endo, Macromolecules, 1994, 27, 620-621; (b) A. Duda, A. Kowalski, S. Penczek, H. Uyama and S. Kobayashi, Macromolecules, 2002, 35, 4266-4270; (c) T. Fuoco, A. Meduri, M. Lamberti, V. Venditto, C. Pellecchia and D. Pappalardo, Polym. Chem., 2015, 6, 1727-1740; (d) T. Witt, M. Häußler and S. Mecking, Macromol. Rapid Commun., 2017, 38, 1600638; (e) T. Witt and S. Mecking, Green Chem., 2013, 15, 2361-2364.

7 D. K. Schneiderman and M. A. Hillmyer, Macromolecules, 2016, 49, 2419-2428.

8 (a) L. van der Mee, F. Helmich, R. de Bruijn, J. Vekemans, A. R. A. Palmans and E. W. Meijer, Macromolecules, 2006, 39, 5021-5027; (b) B. Manzini, P. Hodge and A. Ben-Haida, Polym. Chem., 2010, 1, 339-346; (c) S. Strandman, J. E. Gautrot and X. X. Zhu, Polym. Chem., 2011, 2, 791-799; (d) M. P. F. Pepels, I. Hermsen, G. J. Noordzij and R. Duchateau, Macromolecules, 2016, 49, 796-806.

9 (a) H. Kikuchi, H. Uyama and S. Kobayashi, Polym. J., 2002, 34, 835-840; (b) M. A. J. Veld, A. R. A. Palmans and E. W. Meijer, J. Polym. Sci., Part A: Polym. Chem., 2007, 45, 5968-5978.

10 (a) Z. Jedliński, M. Juzwa, G. Adamus, M. Kowalczuk and M. Montaudo, Macromol. Chem. Phys., 1996, 197, 29232929; (b) Z. Zhong, P. J. Dijkstra and J. Feijen, Macromol. Chem. Phys., 2000, 201, 1329-1333; (c) Y. Wang and
M. Kunioka, Macromol. Symp., 2005, 224, 193-205; (d) Y. Nakayama, N. Watanabe, K. Kusaba, K. Sasaki, Z. Cai, T. Shiono and C. Tsutsumi, J. Appl. Polym. Sci., 2011, 121, 2098-2103; (e) M. P. F. Pepels, M. Bouyahyi, A. Heise and R. Duchateau, Macromolecules, 2013, 46, 4324-4334; (f) M. Bouyahyi and R. Duchateau, Macromolecules, 2014, 47, 517-524; $(g)$ J. A. Wilson, S. A. Hopkins, P. M. Wright and A. P. Dove, Polym. Chem., 2014, 5, 2691-2694; (h) T. Fuoco, A. Meduri, M. Lamberti, V. Venditto, C. Pellecchia and D. Pappalardo, Polym. Chem., 2015, 6, 1727-1740; (i) S. Naumann, P. B. V. Scholten, J. A. Wilson and A. P. Dove, J. Am. Chem. Soc., 2015, 137, 14439-14445.

11 (a) A. Pascual, J. R. Leiza and D. Mecerreyes, Eur. Polym. J., 2013, 49, 1601-1609; (b) A. Pascual, H. Sardon, A. Veloso, F. Ruiperez and D. Mecerreyes, ACS Macro Lett., 2014, 3, 849-853; (c) S. Naumann, A. W. Thomas and A. P. Dove, ACS Macro Lett., 2016, 5, 134-138; (d) V. Ladelta, P. Bilalis, Y. Gnanou and N. Hadjichristidis, Polym. Chem., 2017, 8(3), 511-515.

12 M. P. F. Pepels, I. Hermsen, G. J. Noordzij and R. Duchateau, Macromolecules, 2016, 49, 796-806.

13 (a) C. Bakewell, T.-P.-A. Cao, N. Long, X. F. Le Goff, A. Auffrant and C. K. Williams, J. Am. Chem. Soc., 2012, 134, 20577-20580; (b) C. Bakewell, T.-P.-A. Cao, X. F. Le Goff, N. J. Long, A. Auffrant and C. K. Williams, Organometallics, 2013, 32, 1475-1483; (c) C. Bakewell, A. J. P. White, N. J. Long and C. K. Williams, Angew. Chem., Int. Ed., 2014, 53, 9226-9230; (d) C. Bakewell, A. J. P. White, N. J. Long and C. K. Williams, Inorg. Chem., 2015, 54, 2204-2212; (e) D. Myers, A. J. P. White, C. M. Forsyth, M. Bown and C. K. Williams, Angew. Chem., Int. Ed., 2017, 56, 5277-5282.

14 (a) B. V. Lebedev, A. A. Yevstropov and Y. G. Kiparisova, Vysokomol. Soedin., Ser. A, 1983, 25, 1679; (b) A. Duda and A. Kowalski, Thermodynamics and Kinetics of RingOpening Polymerization, in Handbook of Ring-Opening Polymerization, ed. P. Dubois, O. Coulembier and J.-M. Raque, Wiley-VCH Verlag GmbH \& Co. KGaA, Weinheim, Germany, 2009, pp. 1-51. 